\title{
Selective Bilateral Amygdala Lesions in Rhesus Monkeys Fail to Disrupt Object Reversal Learning
}

\author{
Alicia Izquierdo and Elisabeth A. Murray \\ Section on the Neurobiology of Learning and Memory, Laboratory of Neuropsychology, National Institute of Mental Health, National Institutes of Health, \\ Bethesda, Maryland 20892
}

\begin{abstract}
Neuropsychological studies in nonhuman primates have led to the view that the amygdala plays an essential role in stimulus-reward association. The main evidence in support of this idea is that bilateral aspirative or radiofrequency lesions of the amygdala yield severe impairments on object reversal learning, a task that assesses the ability to shift choices of objects based on the presence or absence of food reward (i.e., reward contingency). The behavioral effects of different lesion techniques, however, can vary. The present study therefore evaluated the effects of selective, excitotoxic lesions of the amygdala in rhesus monkeys on object reversal learning. For comparison, we tested the same monkeys on a task known to be sensitive to amygdala damage, the reinforcer devaluation task. Contrary to previous results based on less selective lesion techniques, monkeys with complete excitotoxic amygdala lesions performed object reversal learning as quickly as controls. As predicted, however, the same operated monkeys were impaired in making object choices after devaluation of the associated food reinforcer. The results suggest two conclusions. First, the results demonstrate that the amygdala makes a selective contribution to stimulus-reward association; the amygdala is critical for guiding object choices after changes in reward value but not after changes in reward contingency. Second, the results implicate a critical contribution to object reversal learning of structures nearby the amygdala, perhaps the subjacent rhinal cortex.
\end{abstract}

Key words: emotion; stimulus-reward association; decision making; reward value; reward contingency; macaque monkey; rhinal cortex; reinforcement

\section{Introduction}

Stimulus-reward association is the ability to link neutral stimuli with reinforcers such as foods, fluids, or certain drugs. Historically, tasks such as object reversal learning and win-stay, loseshift have been used to assess this ability in nonhuman primates; both tasks require the subject to choose objects according to the presence or absence of a food reward. Profound impairments on these tasks follow radiofrequency or aspirative lesions of the amygdala in monkeys (Schwartzbaum and Poulos, 1965; Barrett, 1969; Jones and Mishkin, 1972; Aggleton and Passingham, 1981; Spiegler and Mishkin, 1981), and these findings have been widely interpreted as supporting a role for the amygdala in forming stimulus-reward associations.

Conclusions based on these previous studies must be reconsidered, however, for two related reasons. First, there is accumulating evidence in monkeys that the effects of aspirative lesions and axon-sparing excitotoxic lesions of the amygdala can differ (Murray, 1992; Baxter and Murray, 2000). Second, damage to

\footnotetext{
Received Aug. 21, 2006; revised Nov. 2, 2006; accepted Nov. 21, 2006.

This work was supported by the Intramural Research Program of the National Institute of Mental Health. We thank the staff of the Nuclear Magnetic Resonance Facility, National Institute of Neurological Disorders and Stroke, for assistance obtaining MR scans, P.-Y.Chen for help preparing figures, and K. Wright and R. K. Suda for help testing monkeys.

Correspondence should be addressed to Dr. Alicia Izquierdo, California State University, Los Angeles, College of Natural and Social Sciences, Department of Psychology, 5151 State University Drive, Los Angeles, CA 90032. E-mail: Alzquie@calstatela.edu.

D0I:10.1523/JNEUROSCI.3616-06.2007

Copyright $\odot 2007$ Society for Neuroscience $\quad$ 0270-6474/07/271054-09\$15.00/0
}

structures nearby the amygdala mimics some of the effects of aspirative amygdala lesions. For example, Malkova et al. (1997) found that macaque monkeys with excitotoxic lesions of the amygdala learned visual discriminations for auditory secondary reinforcement at the same rate as controls, which contradicted results from aspirative lesions (Gaffan and Harrison, 1987). Instead, damage to inferotemporal cortex appears to be responsible for the impairment (Baxter et al., 1999; Baxter and Murray, 2000). Together with evidence that aspirative removals of the amygdala disrupt the efferent projections of the rhinal cortex (Goulet et al., 1998), these findings indicate that damage to fibers passing near or through the amygdala, rather than loss of the cell bodies of the amygdala, accounts for some behavioral deficits observed after the aspirative removals. Given that lesions of rhinal cortex severely disrupt object reversal learning (Murray et al., 1998), it is possible that transection of rhinal cortical efferents, rather than amygdala damage, is responsible for the object reversal learning impairment seen after aspirative amygdala lesions.

To test this possibility, monkeys with bilateral, excitotoxic lesions of the amygdala and unoperated controls were trained on a single visual discrimination problem followed by nine serial reversals. For comparison, we tested these same monkeys (both before and after training on object reversal learning) on a task known to be sensitive to selective amygdala damage, the reinforcer devaluation task (Malkova et al., 1997). Whereas object reversal learning evaluates monkeys' choices of objects after changes in reward contingency, reinforcer devaluation assesses 
monkeys' choices of objects after changes in reward value. If monkeys with excitotoxic lesions of the amygdala are impaired on both object reversal learning and reinforcer devaluation, this would indicate that effects of amygdala damage mirror the effects of orbital prefrontal cortex (PFo) damage, because PFo lesions likewise lead to impairments on both tasks (Izquierdo et al., 2004). Alternatively, if monkeys with excitotoxic lesions of the amygdala are impaired on reinforcer devaluation but not object reversal learning, the results would indicate that, unlike PFo, the amygdala mediates response selection based on changes in reward value, but not reward contingency.

\section{Materials and Methods}

\section{Subjects}

Nine experimentally naive monkeys (Macaca mulatta), all male, were used. They weighed $5.2-7.2 \mathrm{~kg}$ at the beginning of the study, were housed individually in rooms with automatically regulated lighting (12 h light/ dark; lights on at 7:00 A.M.), and were maintained on primate chow (no. 5038; PMI Feeds, St. Louis, MO) supplemented with fruit. Monkeys were fed a controlled diet to ensure sufficient motivation and a healthy body weight. Water was always available in the home cage. Four unoperated monkeys (group Con) were tested concurrently with five monkeys assigned to the experimental group (group Amyg). All monkeys were given the behavioral tests in the order described below (see Behavioral testing procedures). These same monkeys received tests of emotional responsiveness, reported previously (Izquierdo et al., 2005), which were performed immediately before and after object reversal learning. In addition, a test of instrumental extinction was given after the food preference retest (Izquierdo and Murray, 2005).

\section{Apparatus and materials}

Monkeys were trained in a modified Wisconsin general testing apparatus (WGTA) located in a dark room. The test compartment was illuminated with two incandescent $60 \mathrm{~W}$ bulbs, whereas the test room and monkey's compartment were always unlit. The test tray, measuring $19.2 \mathrm{~cm}$ (width) $\times 72.7 \mathrm{~cm}$ (length) $\times 1.9 \mathrm{~cm}$ (height), contained two food wells $290 \mathrm{~mm}$ apart, center to center, on the midline of the tray. The wells were $38 \mathrm{~mm}$ in diameter and $6 \mathrm{~mm}$ deep. For pretraining, several dark gray matboard plaques measuring $76 \mathrm{~mm}$ on each side and three junk objects dedicated to this phase were used. For visual discrimination problems used in assessing monkeys' responses to reinforcer devaluation, two sets each consisting of 120 "junk" objects that varied widely in color, shape, size, and texture, designated object sets 1 and 2, were available. For reversal learning, two additional objects, novel at the beginning of testing, were used throughout. A half-peanut served as the food reward. Foods used in reinforcer devaluation and food preference tests included the following: a single $300 \mathrm{mg}$ banana-flavored pellet (P. J. Noyes, Lancaster, $\mathrm{NH}$ ), one-half peanut, a raisin, a sweetened dried cranberry (Craisins; Ocean Spray, Lakeville-Middleboro, MA), a fruit snack (Giant Food, Landover MD), or a chocolate candy (M\&Ms; Mars Candies, Hackettstown, NJ).

\section{Surgery}

Monkeys in the experimental group received bilateral amygdala lesions in two stages. Two monkeys received injections of excitotoxin into the amygdala of the left hemisphere as the first operation (Amyg-1 and Amyg-3), and three monkeys received injections into the amygdala in the right hemisphere as the first operation (Amyg-2, Amyg-4, and Amyg-5). During the second stage surgery, each monkey received injections of excitotoxin into the remaining amygdala in the intact hemisphere. Anesthesia was induced with ketamine hydrochloride $(10 \mathrm{mg} / \mathrm{kg}$, i.m. ) and was maintained with isoflurane (1.0-3.0\%, to effect). Aseptic procedures were used. Heart rate, respiration rate, blood pressure, expired $\mathrm{CO}_{2}$, and body temperature were monitored throughout the procedure, and isotonic fluids were given throughout the procedure as well.

The preoperative and postoperative treatment regimen consisted of dexamethasone sodium phosphate $(0.4 \mathrm{mg} / \mathrm{kg}, \mathrm{i} . \mathrm{m}$.) and Cefazolin antibiotic ( $15 \mathrm{mg} / \mathrm{kg}$, i.m.) for $1 \mathrm{~d}$ before surgery and 1 week after surgery, to reduce swelling and prevent infection, respectively. At the end of surgery, and for 2 additional days, the monkeys received the analgesic ketoprofen (10-15 mg, i.m.); ibuprofen $(100 \mathrm{mg})$ was provided for 5 additional days.

For injections of excitotoxin into the amygdala, we used methods described previously (Malkova et al., 1997; Baxter et al., 2000; Izquierdo and Murray, 2004a). Briefly, after noting the location of the sagittal sinus as the landmark for mediolateral coordinates, we calculated 18-22 injection sites based on magnetic resonance (MR) imaging scans performed an average of $5.1 \mathrm{~d}$ before surgery. Because one to four sites were located along each needle track, the entire series typically involved a total of nine needle penetrations. At each site, spaced approximately $2 \mathrm{~mm}$ apart in each plane, we injected $0.6-1.0 \mu \mathrm{l}$ of ibotenic acid $(10 \mu \mathrm{g} / \mu \mathrm{l} ; 0.2 \mu \mathrm{l} / \mathrm{min}$; Biosearch Technologies, Novato, CA) into the amygdala via the 30 -gauge needle of a Hamilton syringe. The needle remained in place 2-3 min after each injection to limit diffusion of the toxin up the needle track. The intended lesion (Fig. 1) included the entire amygdala, including both basolateral and centromedial groups.

\section{Assessment of amygdala lesions}

The extent of amygdala damage was evaluated from T2-weighted scans obtained within $12 \mathrm{~d}$ of surgery. The extent of hypersignal in this type of scan has previously been shown to accurately reflect the extent of neuronal loss as estimated from traditional methods (i.e., light microscopic evaluation of Nissl-stained material), at least for medial temporal lobe structures such as the perirhinal cortex, parahippocampal cortex, and hippocampus (Malkova et al., 2001; Nemanic et al., 2002). Details for specific methods of lesion assessment have been provided previously (Izquierdo and Murray, 2004a). In brief, the region of hypersignal evident in the T2-weighted MR images obtained postoperatively was plotted onto coronal sections, spaced at $1 \mathrm{~mm}$ intervals, of a standard rhesus monkey brain. The surface area of this region was measured on each section, and then the area measurements were added to determine volume. The volume of the affected region was expressed as a function of the volume of the entire amygdala. Because of our inability to obtain a postoperative MR scan, only one hemisphere could be evaluated in monkey Amyg-2. For all five monkeys in group Amyg, the damage was essentially as intended (Table 1). Monkeys in this group sustained a mean of $93.4 \%$ damage (range, $85.2-100 \%$ ). Each of the monkeys with amygdala lesions sustained some inadvertent damage to adjacent structures. Amyg-1 and Amyg-5 sustained slight bilateral unintended damage to anterior portions of the entorhinal cortex and hippocampus and to portions of the ventral claustrum, substantia innominata, and piriform cortex. The remaining monkeys in this group sustained only minor and unilateral damage to a subset of these regions. Representative cases are shown in Figure 1.

\section{Behavioral testing procedures}

All operated monkeys underwent acclimation, pretraining, and a test of food preference before the first stage of surgery. After they had sustained a unilateral lesion, visual discrimination learning of 60 pairs and responses to reinforcer devaluation (test 1) were administered. After the second stage of surgery, when monkeys were under the influence of a bilateral amygdala lesion, responses to reinforcer devaluation were again assessed (test 2), and then object reversal learning was administered. Finally, monkeys were trained on an additional set of visual discrimination problems (set 2), and then given another test of reinforcer devaluation (test 3 ) and a control procedure to assess satiety (test 4). Controls received the same training (with cessation in training when the experimental monkeys received surgery) but remained unoperated. A schematic diagram of the sequence of surgical operations and behavioral tests is shown in Figure 2. Tasks are described below in the same order in which they were administered.

Accommodation and pretraining. Before formal behavioral testing, monkeys were introduced to the WGTA and allowed to take food freely from the test tray. Then, through successive approximation, monkeys were trained to displace plaques that completely covered the food wells. After the monkeys successfully displaced plaques for food, they were given two to five sessions of additional training with objects; monkeys were required to displace one of three pretraining objects overlying a baited food well. Pretraining was considered complete when monkeys 
Intended
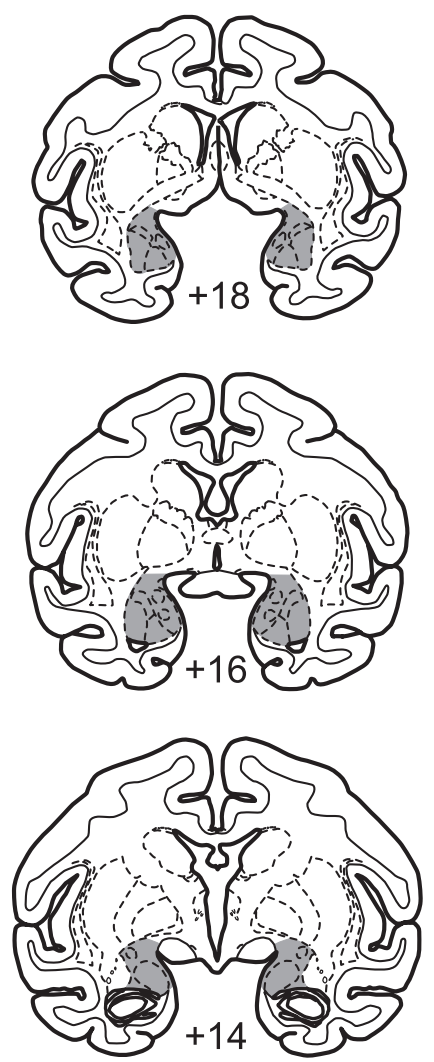

Case Amyg-1
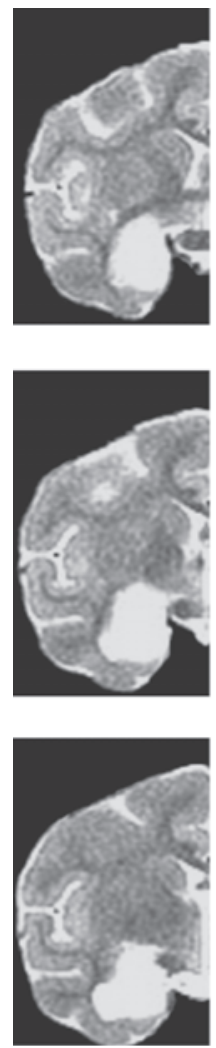
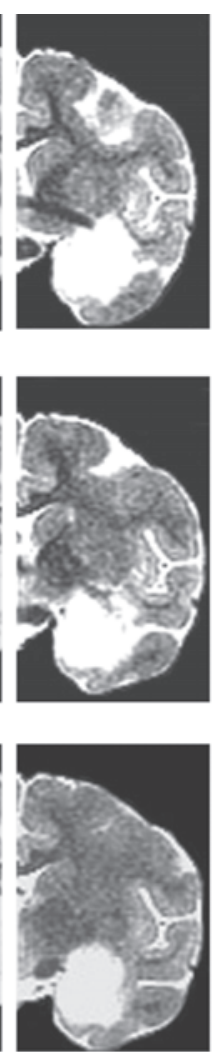

Case Amyg-4
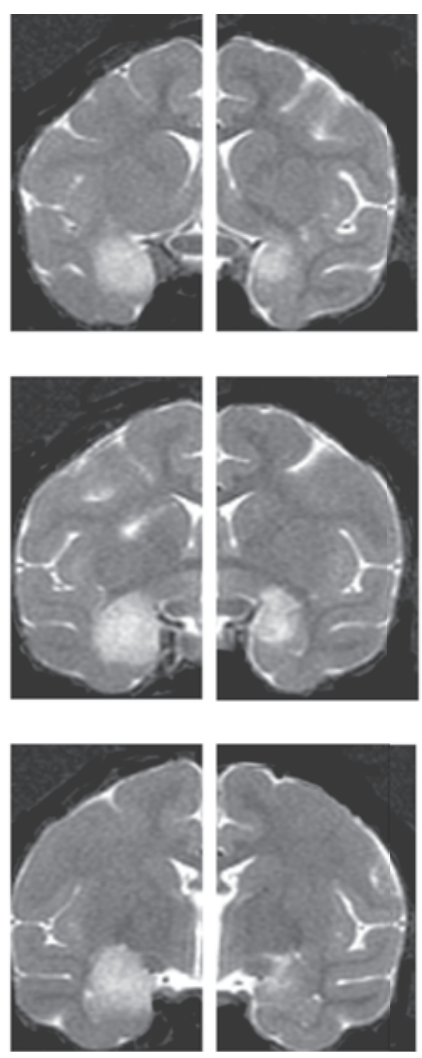

Case Amyg-5
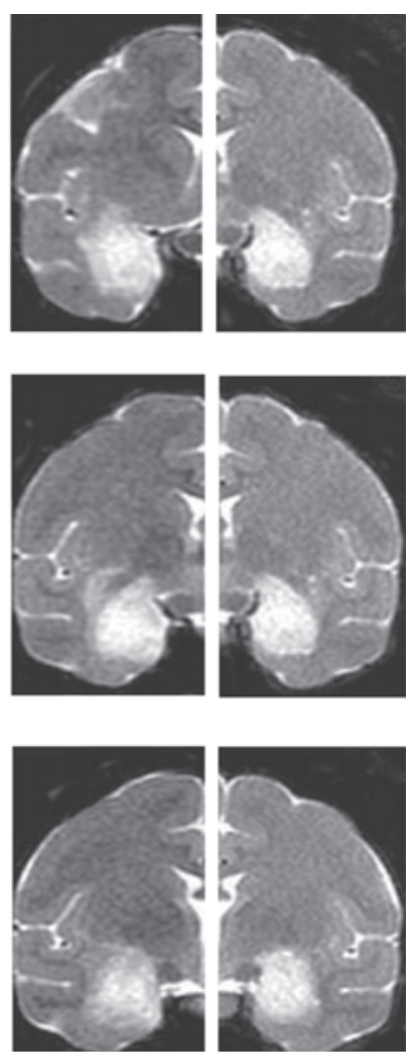

Figure 1. Left column, Coronal sections from a standard rhesus monkey brain showing the intended bilateral amygdala lesion (shaded region). Numerals indicate distance from interaural plane (0). Right columns, MR images from case Amyg-1 (largest lesion), Amyg-4 (smallest lesion), and Amyg-5 (complete lesion) at matching levels. The T2-weighted MR images show the extent of white hypersignal reflecting edema after injections of the excitotoxin, ibotenic acid. The hypersignal also represents the approximate location and extent of the lesion.

Table 1. Percentage damage to amygdala (group Amyg)

\begin{tabular}{lccc}
\hline Monkey & Left & Right & Mean \\
\hline Amyg-1 & 100 & 100 & 100 \\
Amyg-2 & - & 98.5 & 98.5 \\
Amyg-3 & 94.7 & 77.3 & 86.0 \\
Amyg-4 & 100 & 70.4 & 85.2 \\
Amyg-5 & 100 & 100 & 100 \\
\hline
\end{tabular}

Numerals indicate percentage damage to amygdala sustained by each of the operated monkeys. Amyg-1 to Amyg-5, Monkeys with excitotoxic amygdala lesions; Left, left hemisphere; Right, right hemisphere; Mean, average of the values for the left and right hemispheres.

successfully displaced each of the three objects presented to them singly for a total of 30 trials.

Food preference test. Before surgery, all monkeys were assessed for their preferences for six different foods. On each trial, monkeys were presented with two different foods, one in each food well, and allowed to choose only one of the two foods. The choice was noted by the experimenter. All food types were encountered 10 times during each session; each food was paired with each of the other foods twice, with the left-right positions counterbalanced within a single session. The different food pairs were presented in pseudorandom order each day. Test sessions comprised 30 trials each separated by $10 \mathrm{~s}$. Monkeys were tested for a total of $15 \mathrm{~d}$.

The data for each monkey were tabulated in terms of total number of choices of each food across the last $5 \mathrm{~d}$ of testing, after food preferences had stabilized. In addition, we tabulated choices for each possible pairing of two foods, because this was a more specific indication of relative palatability. Two foods that were approximately equally preferred were selected for each monkey; these were designated as Food 1 and Food 2.

Visual discrimination learning of 60 pairs (set 1). After receiving the first stage surgery (or after an equivalent period of rest for controls), monkeys were trained to discriminate 60 pairs of objects. This discrimination learning phase was a prerequisite for assessing the effects of reinforcer devaluation, described in the next paragraph. For each pair of objects, one object was arbitrarily designated as the $S+$ (i.e., baited with a food reward) and the other as the S- (i.e., unbaited). Thirty of the S+ were assigned to be baited with Food 1 and the other 30 with Food 2. On each trial, an S+ and an S- were presented together for choice, each overlying one of the two food wells on the test tray. If the monkey displaced the S+, it was allowed to take and eat the food reward hidden underneath. If instead the monkey chose the S-, the trial was terminated without correction. Each pair of objects appeared in only one trial per session in the same order every day, for a total of 60 trials per daily session. The positive and negative assignment of objects and the food reward assignments remained constant across days; the left-right position of positive objects followed a pseudorandom order. Trials were separated by $20 \mathrm{~s}$. Criterion was set at a mean of $90 \%$ correct responses over 5 consecutive days (i.e., 270 or more correct responses in 300 trials).

Reinforcer devaluation test 1 . After the monkeys had attained criterion, their choices of objects were assessed in four critical sessions comprising test 1 . In these sessions, all the $\mathrm{S}-$ were set aside, and only the S+ were used. Thirty pairs of objects, each consisting of one Food 1 object and one Food 2 object, were presented to the monkey for choice. On each trial, both objects were baited with the same foods that they had been paired with during the visual discrimination learning phase. The monkeys were allowed to choose only one of the objects in the pair to obtain the food reward hidden underneath. Two of the four critical test sessions were preceded by a selective satiation procedure, described below, intended to devalue one of the two foods. The other two sessions were preceded by no satiation procedure and served as baseline measures. Because any longterm effects of the satiation procedures might affect subsequent critical 


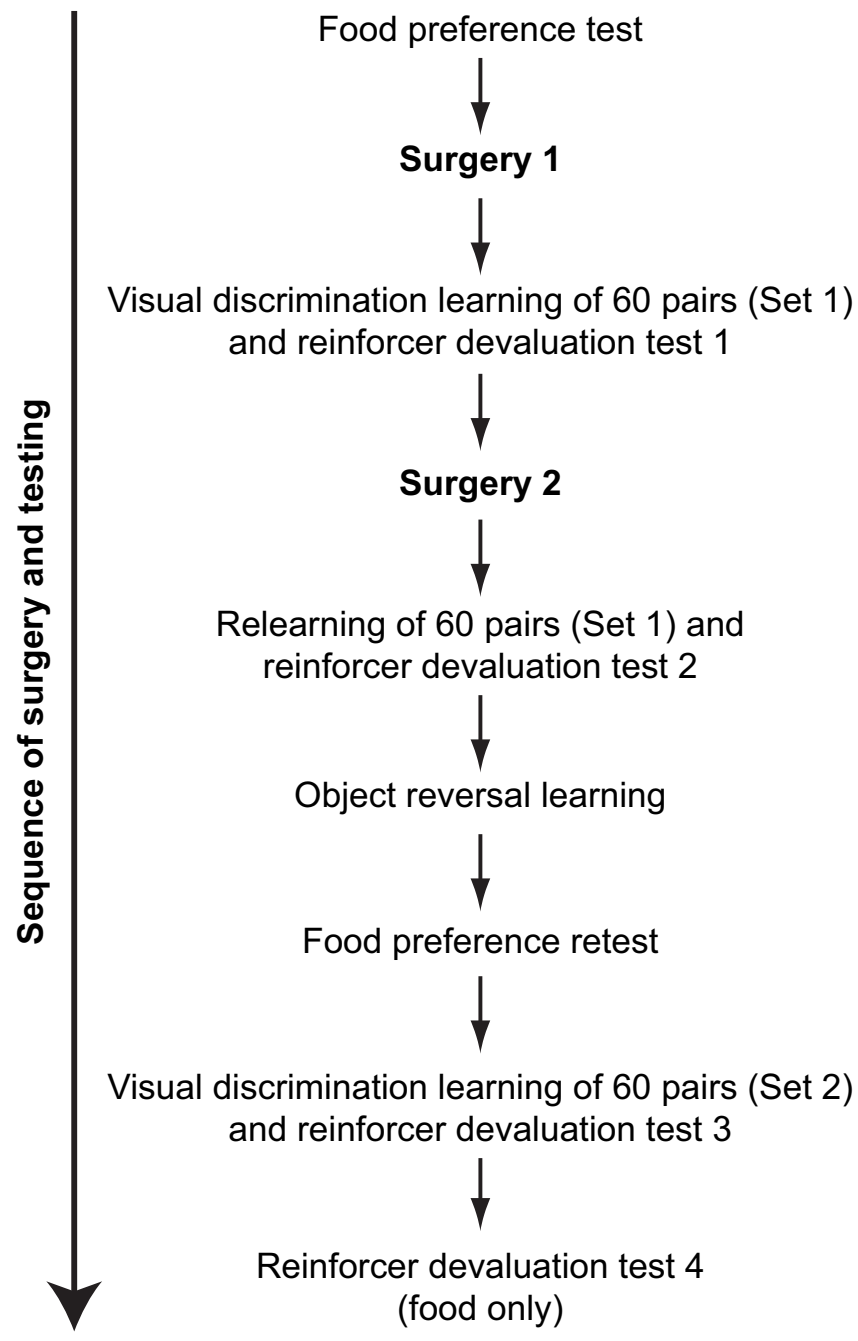

Figure 2. Schematic depiction of the sequence of surgical operations and behavioral testing.

sessions, at least $2 \mathrm{~d}$ of rest followed each session that had been preceded by selective satiation. In addition, to test whether the effects of the selective satiation procedure were temporary, as intended, the monkeys were given one regular training session between each critical session. This session consisted of presentation of the original 60 pairs of objects presented in the same manner as during original learning. Critical sessions occurred in the following order for each monkey: (1) first baseline session, (2) session preceded by selective satiation with Food 1, (3) second baseline session, and (4) session preceded by selective satiation with Food 2. The unit of analysis, the "difference score," was the change in choices of object type (Food 1- and Food 2-associated objects) in the sessions preceded by selective satiation compared with baseline sessions.

Selective satiation. For the selective satiation procedure, a food box measuring $7.7 \mathrm{~cm}$ (width) $\times 10.3 \mathrm{~cm}$ (length) $\times 7.7 \mathrm{~cm}$ (height) and attached to the monkey's home cage was filled with a known quantity of either Food 1 or Food 2 while the monkey was in its home cage. The monkey was then left to eat unobserved for $15 \mathrm{~min}$, at which point the experimenter checked to see whether all of the food had been eaten. If it had, the monkey's food box was refilled. Whether additional food was given or not, when $30 \mathrm{~min}$ had elapsed from the time the satiation procedure was initiated, the experimenter started observing the monkey through a window in the door to the animal housing room. The procedure was considered complete when the monkey refrained from taking food for 5 consecutive minutes. The test session in the WGTA was then initiated within $10 \mathrm{~min}$. For baseline sessions, the monkey was simply taken from its home cage to the WGTA without undergoing a selective satiation procedure.
Relearning and reinforcer devaluation test 2. After the second-stage surgery for the operated group and after a period of rest for the controls, all monkeys were retrained on the original set of object discriminations to the same criterion as before. Relearning was initiated an average of $27.6 \mathrm{~d}$ after the second stage surgery for the operated group. The elapsed time between the completion of test 1 and relearning was $60.4 \mathrm{~d}$ for the monkeys with amygdala lesions and $38.8 \mathrm{~d}$ for the controls. After the monkeys had reattained criterion, the reinforcer devaluation test was repeated in exactly the same manner described above.

Object reversal learning. Approximately 3.0 months after the second stage surgery or rest, and after having completed reinforcer devaluation test 2 , each monkey was trained on a single visual discrimination problem and its reversal. We used the same method reported previously (Izquierdo and Murray, 2004a: Izquierdo et al., 2004). On the first trial of initial learning, both objects were either baited or unbaited (counterbalanced within group), and the object chosen designated as either the $\mathrm{S}+$ (if it had been baited) or the S- (if it had been unbaited). Thus, the monkeys' choices on trial 1 determined the designation of the S+ and Sfor initial learning, a procedure intended to prevent bias caused by object preferences. On each trial thereafter, the two objects were presented, one baited and one unbaited, and one each overlying the two food wells. The monkey was allowed to displace only one of the two objects and, if correct, to retrieve the food reward underneath. There was no correction after errors. The intertrial interval was $10 \mathrm{~s}$ and the left-right position of the correct object followed a pseudorandom order. Monkeys were tested at the rate of 30 trials per daily test session for 5 or $6 \mathrm{~d}$ per week. Criterion was set at 28 correct responses in 30 trials $(93 \%)$ on $1 \mathrm{~d}$, followed by at least 24 correct in 30 trials $(80 \%)$ the next day. After monkeys attained criterion on the original problem, the reward contingencies were reversed (starting the next day) and each monkey was trained to the same criterion as before. This procedure was repeated until a total of nine serial reversals had been completed.

Food preference retest. An average of 10.0 months after the second-stage surgery, monkeys were evaluated for their food preferences a second time to examine whether the rankings of foods had changed. The method was the same as that used before.

Visual discrimination learning of 60 pairs (set 2) and reinforcer devaluation test 3 . Monkeys were required to learn a novel set of 60 pairs of objects (set 2) and were then tested for their responses to reinforcer devaluation (test 3 ) using the same two foods as before. This assessment took place an average of 19.2 months after the second surgery.

Reinforcer devaluation test 4 (foods only). Finally, monkeys were evaluated for the effect of reinforcer devaluation on choices of foods directly (test 4), without the intervening objects. This test was performed to determine whether the effects of satiety transferred from the home cage to the test apparatus, as we assumed.

\section{Results}

\section{Visual discrimination learning and relearning (set 1)}

The two groups of monkeys did not differ in the number of errors scored in initial learning of the 60 discrimination problems (mean errors to criterion: controls, 226.5; unilateral amygdala, $\left.185.8 ; t_{(7)}=-1.09 ; p=0.31\right)$. The reacquisition of these problems after the second-stage surgery or rest also did not differ between groups (mean errors to reattain criterion: controls, 3.0; bilateral amygdala, $\left.18.8 ; t_{(7)}=0.98 ; p=0.36\right)$. The same pattern of results was obtained for trials to criterion.

\section{Reinforcer devaluation tests 1 and 2}

Scores on reinforcer devaluation tests 1 and 2 are shown in Figure 3. On both tests, control monkeys tended to avoid choosing objects overlying the devalued food in favor of the remaining object, thereby exhibiting adaptive response selection. On average, monkeys with amygdala lesions showed less of this tendency. The difference scores were analyzed using a $2 \times 2$ ANOVA with between-subjects factor of group (Amyg, Con) and withinsubjects factor of stage (test 1 , test 2 ). The analysis revealed a 


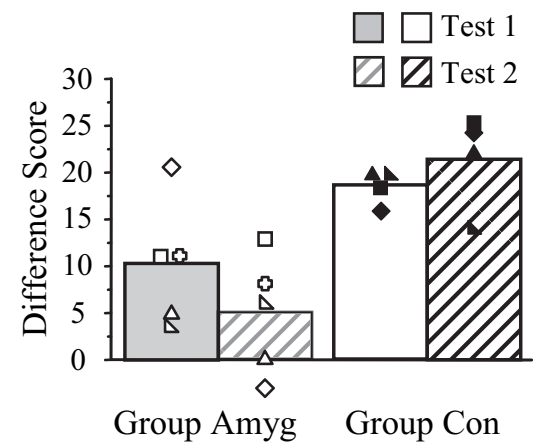

Figure 3. Difference scores of monkeys with amygdala lesions (open symbols) relative to unoperated controls (filled symbols). The higher the bar, the greater the response to changes in reinforcer value. At the time of test 1 , the monkeys in group Amyg had sustained unilateral lesions, whereas at the time of test 2 , they had sustained bilateral lesions. The symbols represent scores for individual monkeys: open triangle, Amyg-1; open square, Amyg-2; open rightangled triangle, Amyg-3; open diamond, Amyg-4; open plus sign, Amyg-5; closed triangle, Con-1; closed square, Con-2; closed right-angled triangle, Con-3; closed diamond, Con-4.

highly significant main effect of group $\left(F_{(1,7)}=32.77 ; p<0.01\right)$ but no effect of stage $\left(F_{(1,7)}=0.18 ; p=0.68\right)$, reflecting the substantial impact of a unilateral lesion on this task. A previous study also found significant disruption of reinforcer devaluation effects after unilateral amygdala lesions (Izquierdo and Murray, 2004a). Unlike what has been reported previously using crossedlesion methodology (Baxter et al., 2000), however, there was no significant interaction of group by stage $\left(F_{(1,6)}=1.72 ; p=0.23\right)$.

The amount of food consumed by the two groups during the satiation procedures did not differ on any of the tests (mean grams eaten, test 1: controls, 120.5, unilateral amygdala, 152.9, $t_{(7)}=0.73, p=0.49$; test 2 : controls, 146.5 , bilateral amygdala, $204.3, t_{(7)}=1.21, p=0.27$; test 3 : controls, 171.9 , bilateral amygdala, $143.7, t_{(7)}=-0.76, p=0.47$; test 4 : controls, 203.3, bilateral amygdala, 143.7, $\left.t_{(7)}=-1.19, p=0.27\right)$. The amount of food consumed by each of the two groups (analyzed separately) did not correlate with difference scores (unilateral or bilateral amygdala: $-0.52<r$ values $<0.71, p$ values $>0.22$; controls: $-0.91<$ $r$ values $<0.37, p$ values $>0.13)$.

\section{Visual discrimination learning of 60 pairs (set 2)}

The two groups acquired this novel set of object discrimination problems at the same rate (mean errors to criterion: controls, 311.3; bilateral amygdala, $\left.158.2 ; t_{(7)}=-1.61 ; p=0.15\right)$. Trials to criterion also did not differ by group.

\section{Reinforcer devaluation tests 3 and 4}

Difference scores for tests 3 and 4 are shown in Figure 4 . The difference scores were analyzed using a $2 \times 2$ ANOVA with between-subjects factor of group (Amyg, Con) and withinsubjects factor of condition (object plus food, food only). The analysis revealed a marginal effect of group $\left(F_{(1,7)}=3.91 ; p=\right.$ $0.088)$, a highly significant effect of condition $\left(F_{(1,7)}=38.85 ; p<\right.$ $0.01)$, and a marginally significant interaction of group by condition $\left(F_{(1,6)}=4.32 ; p=0.076\right)$. Post hoc $t$ tests corrected for multiple comparisons show that group Amyg was impaired relative to group Con on test $3\left(t_{(7)}=-2.73 ; p=0.03\right)$, but not on test 4 $\left(t_{(7)}=-1.20 ; p=0.27\right)$.

\section{Objects "stolen" during learning, relearning, and learning of} novel set

Excessive object manipulation has been reported after bilateral temporal lobe damage (Klüver and Bucy, 1939) and after same-

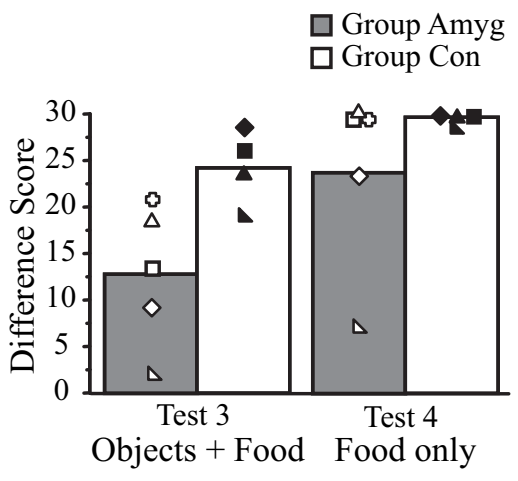

Figure 4. Mean difference scores of monkeys on two tests of reinforcer devaluation: a test administered with objects overlying food rewards (test 3) and a test with food rewards presented alone (test 4). Monkeys with bilateral amygdala lesions showed attenuated performance when choosing between objects, but not when choosing directly between two foods. The symbols represent scores for individual monkeys: open triangle, Amyg-1; open square, Amyg-2; open right-angled triangle, Amyg-3; open diamond, Amyg-4; open plus sign, Amyg-5; closed triangle, Con-1; closed square, Con-2; closed right-angled triangle, Con-3; closed diamond, Con-4. Group Amyg, Monkeys with bilateral excitotoxic lesions of the amygdala; group Con, unoperated control monkeys.

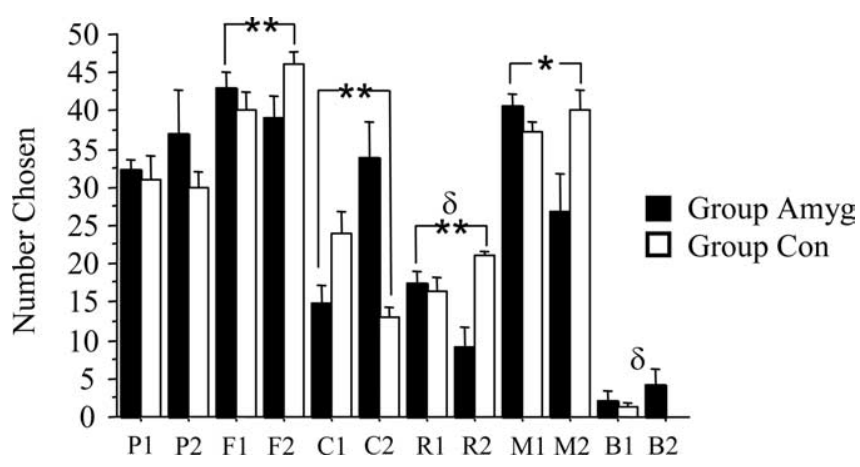

Figure 5. Mean number of food choices made by monkeys at two different time points (stages) separated by $\sim 1$ year. For group Amyg, test 1 took place before the first surgery, and test 2 took place approximately 10 months after the second surgery. Asterisks represent foods for which a significant interaction of group by stage was found $\left({ }^{* *} p<0.02 ;^{*} p<0.07\right)$, and $\delta$ represents a significant main effect of group. $P$, Half-peanut; $F$, fruit snack; $C$, craisin; $R$, raisin; $M$, M\&M; B, banana pellet. Group Amyg, Monkeys with bilateral excitotoxic lesions of the amygdala $(n=5)$; group Con, unoperated control monkeys $(n=4)$. Error bars indicate SEM.

hemisphere, unilateral lesions that include both PFo and amygdala (Izquierdo and Murray, 2004a). All five of the operated monkeys in the present study took objects from the test tray to explore manually and orally. Although the two groups did not differ in the frequency of this behavior during learning (objects stolen during learning: controls, 2.3; unilateral amygdala, 27.0; $t_{(7)}=1.48 ; p=0.18$ ) or relearning (objects stolen during relearning: controls, 0 ; bilateral amygdala, $\left.12.8 ; t_{(7)}=1.58 ; p=0.16\right)$ of the initial set of object discrimination problems (set 1 ), they did differ when acquiring a novel set of discrimination problems (set 2) $\sim 19$ months after surgery (controls, 0.25 ; bilateral amygdala, $\left.40.8 ; t_{(7)}=2.27 ; p=0.05\right)$.

\section{Food preference test and retest}

Food choices are shown in Figure 5. To assess whether monkeys' choices of foods changed during the course of the study, data from the last $5 \mathrm{~d}$ of the food preference test and retest were analyzed using $2 \times 2$ repeated-measures ANOVAs with betweensubjects factor of group (Amyg, Con) and within-subjects factor 
of stage (test, retest). In many cases, monkeys with amygdala lesions displayed an opposite pattern of food preferences across the two tests relative to unoperated controls. In monkeys' choices for raisins, craisins, M\&Ms, and fruit snacks (foods with the highest carbohydrate content, respectively: $64.2,82.5,71.4$, and $73.3 \%$ of a $40 \mathrm{~g}$ serving size), there was a significant interaction of group by stage $(4.67<F$ values $<19.89 ; 0.003<p$ values $<0.067)$, although it should be noted that there was a difference between groups in preference for craisins even preoperatively $\left(t_{(7)}=\right.$ $-2.46 ; p=0.04)$. Nonetheless, whereas group Con showed an increase in the selection of three of the four foods across the two tests, group Amyg showed a decrease. In addition, there was a main effect of group in monkeys' preference for raisins $\left(F_{(1,7)}=\right.$ $10.03 ; p=0.02)$ and banana pellets $\left(F_{(1,7)}=5.82 ; p=0.05\right)$. Only choices of peanuts showed no group or group by stage effects. Given this unexpected set of results, we performed two additional analyses, described below, to evaluate whether the changes in food choices could account for group differences in response to reinforcer devaluation.

Food preference index of change

Based on the data obtained from the food preference test and retest, a "food preference index of change" was computed for each monkey. The index was defined as the sum of the differences in each of these food choices across the two preference tests (food preference index of change: group Amyg, -59; group Con, +38). An analysis of correlation between devaluation difference scores and food preference index of change scores revealed no significant association for either group. Thus, the shifts in food choices appear to be unrelated to the magnitude of the reinforcer devaluation effects.

\section{Stability of baseline object choices}

Presumably, the changes in food choices noted above reflect gradual changes in food preference that occurred over the course of the study. However, if food choices had shifted rapidly, this could manifest as an instability of the baseline scores, which might in turn influence the reinforcer devaluation difference scores. To test this possibility, we quantified the stability of object choices for baseline sessions, (i.e., for those critical sessions not preceded by selective satiation procedures). A given monkey's choices of Food 1 and Food 2 objects can be expressed as a ratio (number of Food 1 objects/number of Food 2 objects). The stability of this measure can be quantified by calculating the difference between the number of objects of one class (e.g., Food 1 objects) chosen across the two baselines for each test (1-3). For example, if a monkey chose 16:14 on the first baseline and 18:12 on the second, the difference would be the absolute value of 16 minus 18 , or 2 of a possible 30 . For completeness, we performed the same analysis for the food choices in test 4 . In general, the baseline scores were stable. More importantly, there were no significant differences between groups in the stability of their baseline scores on any of the tests (test 1: Amyg, 3.0, Con, 4.3; test 2: Amyg, 3.6, Con, 4.5; test 3: Amyg, 2.0, Con, 3.8; test 4: Amyg, 4.6, Con, 8.8 ; all values of $p>0.18$ ). Given the stability of baseline scores, together with the lack of a systematic relationship between difference scores and changes in food preferences, it is extremely unlikely that alterations in food preference account for the deficit in reinforcer devaluation in group Amyg.

\section{Object reversal learning}

The number of errors scored in acquisition of the initial discrimination and during the nine subsequent reversals is illustrated in

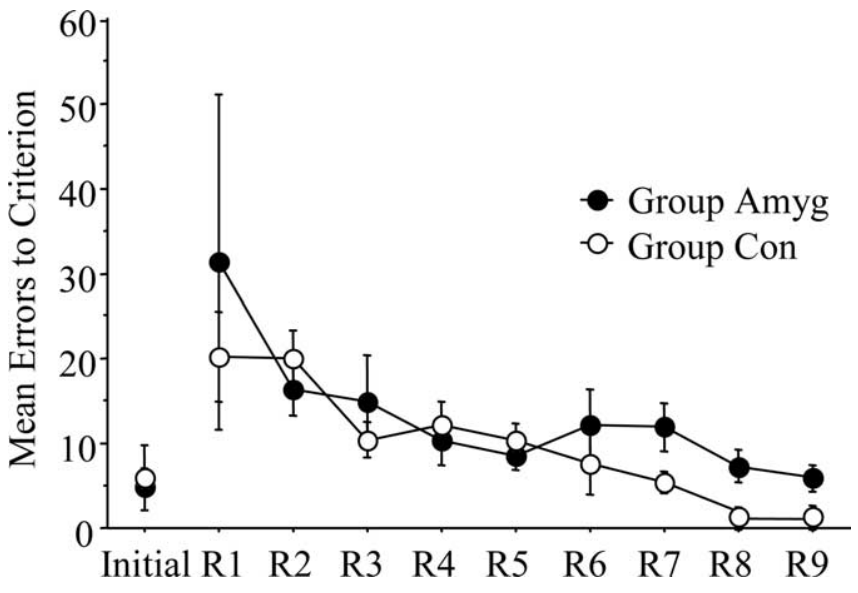

Figure 6. Group mean errors to criterion for initial learning (Initial) and nine serial reversals (R1-R9) in object reversal learning. Group Amyg, Monkeys with bilateral excitotoxic lesions of the amygdala $(n=5)$; group (on, unoperated control monkeys $(n=4)$. Error bars indicate +SEM.

Figure 6. The two groups did not differ in initial learning of the single object discrimination (mean errors to criterion: group Con, 6.0; group Amyg, $5.0 ; t_{(7)}=-0.24 ; p=0.82$ ). An ANOVA with repeated measures on errors to criterion during reversals 1 through 9 revealed no significant effect of group $\left(F_{(1,7)}=0.67\right.$; $p=0.44)$ and no significant group by session interaction $\left(F_{(8,56)}=\right.$ $0.35 ; p=0.94)$. There was, however, a significant effect of session $\left(F_{(8,56)}=2.81 ; p=0.01\right)$, indicating development of a reversal learning set. In addition, mean trials and errors to criterion across all reversals did not differ by group (mean trials to criterion: group Con, 375.0; group Amyg, 468.0; $t_{(7)}=1.14 ; p=0.29$; mean errors to criterion: group Con, 96.8; group Amyg, 124.4; $t_{(7)}=$ $0.76 ; p=0.47)$.

\section{Discussion}

We found that selective, excitotoxic lesions of the amygdala do not cause deficits in object reversal learning, which refutes the widely held view that the amygdala has a general function in stimulus-reward association [Jones and Mishkin, 1972; Spiegler and Mishkin, 1981 (in monkeys); White and McDonald, 2002 (in rats)]. Monkeys with complete, bilateral lesions of the amygdala can choose objects flexibly, based on changes in reward contingency (i.e., which of two objects is associated with reinforcement now). The same monkeys cannot, however, choose objects flexibly based on changes in reward value.

Neural substrates of object reversal learning and related tasks As noted previously, aspirative or radiofrequency lesions of the amygdala in monkeys produce an impairment on object reversal learning (Schwartzbaum and Poulos, 1965; Barrett, 1969; Jones and Mishkin, 1972; Aggleton and Passingham, 1981) and on a win-stay/lose-shift task with trial-unique objects (Spiegler and Mishkin, 1981). In this win-stay/lose-shift task, animals must return to an object that had led to food reward in the preceding acquisition phase, and avoid one that did not. For decades, these findings have been cited as evidence for a general role of the amygdala in stimulus-reward association. In hindsight, however, the conclusion fails on two counts. First, the deficit depends on unintended damage beyond the amygdala. Second, both tasks confound responses based on stimulus-reward association with those based on visually based performance rules. These issues are taken up, in turn, below. 
Contrary to findings obtained with less selective lesion techniques, excitotoxic amygdala lesions fail to disrupt performance on the object reversal task (present study) and have only a mild, transient effect on the win-stay/lose-shift task (Stefanacci et al., 2003). In contrast, bilateral removals limited to the rhinal cortex (Murray et al., 1998) and inferior temporal (IT) cortex (Spiegler and Mishkin, 1981) produce deficits on object reversal learning and win-stay/lose-shift, respectively, that are just as severe as those observed after aspirative removals of the amygdala. Thus, the deficits previously attributed to amygdala damage likely resulted instead from either unintended damage to IT (including rhinal cortex) or to IT connections with prefrontal cortex (PF) (Baxter et al., 1998; Munoz et al., 2001).

Although both object reversal learning and win-stay/loseshift tasks are thought to measure the ability of monkeys to form stimulus-reward associations, it is evident that these and related tasks, such as discrimination learning set, can be learned in at least two ways: via an object-outcome association (i.e., by choosing the object associated with the outcome of higher biological value) and via visually based performance rules (e.g., by choosing the object that is associated in memory with the appearance of a peanut). In the latter case, food provides information independent of its reinforcing value (Gaffan, 1985). Normal performance on tasks involving visually based performance rules requires intact IT-PF interactions. For example, surgical disconnection of IT from PF disrupts preoperatively acquired learning sets (Browning et al., 2007), which rely on win-stay/lose-shift strategies (Murray and Gaffan, 2006), as well as matching-to-sample rules (Parker and Gaffan, 1998; Bussey et al., 2002). This aspect of the object reversal and win-stay/lose-shift tasks probably accounts for both the effects of aspirative amygdala lesions and the deficits caused by bilateral IT lesions.

\section{Neural basis of reinforcer devaluation effects}

Monkeys with selective amygdala lesions showed reduced reinforcer devaluation effects (i.e., a failure to shift choices of objects based on changes in food value), confirming the findings of Malkova et al. (1997). The present study extends those findings by showing that the impairment persists for at least 1 year, and that it occurs in monkeys with intact object reversal learning abilities. We also found that monkeys with amygdala lesions have intact satiety mechanisms and that the effect of satiety transfers from the home cage to the test apparatus. Thus, the impairment on the reinforcer devaluation task that follows amygdala lesions does not result from altered satiety mechanisms or from an inability to discriminate objects or foods. Instead, the deficit results from a difficulty in either updating the value of food or in linking objects to the current value of a food.

By infusing the GABA agonist muscimol into the basolateral amygdala of macaque monkeys, bilaterally, either before or after the selective satiation procedure, Wellman et al. (2005) found that temporary inactivation of the amygdala during the selective satiation procedure, but not afterward, disrupted the reinforcer devaluation effects. This finding shows that the amygdala is no longer essential for guiding object choices once the value of the food has been updated, but is necessary for updating food value and/or linking that value with stimuli.

In addition to the amygdala, PFo (Baxter et al., 2000; Izquierdo et al., 2004) and the medial portion of the mediodorsal nucleus of the thalamus (Izquierdo and Murray, 2004b) are crucial for reinforcer devaluation effects using this object-based task. In contrast, neither the perirhinal cortex nor hippocampus is essential (Chudasama and Murray, 2004), as evaluated with pre- training lesions using the same procedures as in the present study. Accordingly, unlike the deficits discussed above for object reversal learning and the win-stay/lose-shift task, the effects of the selective amygdala lesions reported here do not result from inadvertent damage to structures and pathways near the amygdala. In addition, because the hippocampal lesions involved injection of excitotoxins via needles that traverse many of the same structures as would occur for amygdala lesions, yet were without effect, it is unlikely that mechanical damage arising from needles passing dorsal to the amygdala is responsible for the deficits.

\section{Neural substrates of reward and emotion processing}

In the domain of reward processing and emotion, the effects of amygdala lesions have, historically, closely resembled those of PFo lesions. For example, damage to the amygdala and damage to PFo disrupt both emotional responses (Meunier et al., 1999; Kalin et al., 2001; Stefanacci et al., 2003; Izquierdo et al., 2005) and reinforcer devaluation effects (Malkova et al., 1997; Izquierdo et al., 2004). Until the present study, both structures were thought to be necessary for object reversal learning and, until recent evidence to the contrary (Izquierdo and Murray, 2005), for instrumental extinction as well (Weiskrantz, 1956; Butter et al., 1963). Consequently, several authorities have suggested a common circuitry for both emotion and reward processing (Butter, 1969; Jones and Mishkin, 1972; Aggleton and Passingham, 1981; Rolls, 1999). The present findings refute this idea by showing that selective amygdala lesions, which have a clear effect on emotional processing in the same monkeys studied here (Izquierdo et al., 2005), have no effect on the kind of reward processing required by object reversal learning.

\section{Food choice}

We also found that amygdala lesions caused changes in food preferences. Whereas intact monkeys increasingly preferred foods high in carbohydrates over time, monkeys with selective amygdala lesions showed the opposite trend. Although abnormal food "preferences" follow large, nonselective lesions that include the amygdala (Klüver and Bucy, 1939; Pribram and Bagshaw, 1953; Weiskrantz, 1956) (see also Baylis and Gaffan, 1991), these altered preferences likely reflect the flattening of choices between foods and nonfoods, or between preferred foods and meat. Aggleton and Passingham (1982), who noted this flattening, found no effect of selective amygdala lesions on choices among three familiar foods, in accordance with the results of Murray et al. (1996). A longitudinal comparison of preoperative versus postoperative food choices, as in the present study, appears to be important for observing food preference effects beyond flattening. The amygdala is known to contribute to macronutrient selection, but the precise effects of amygdala damage likely depend on the site of the lesion and composition of the maintenance diet (Ritter and Hutton, 1995; King et al., 1998).

\section{Conclusions}

Recent neurophysiological (Tremblay and Schultz, 1999; Hikosaka and Watanabe, 2000; Wallis and Miller, 2003; PadoaSchioppa and Assad, 2006) and neuropsychological (Holland and Gallagher, 2004) findings suggest that PFo neurons store the value of expected outcomes. We propose that, when monkeys face a choice of objects in the critical sessions of reinforcer devaluation, access to these stored outcomes occurs via interaction of IT, including rhinal cortex, with PFo. When decisions depend on the value of familiar outcomes, this process does not require the amygdala. When food values need to be updated because of 
changes in the animal's biological state, however, the amygdala needs to interact with PFo. Thus, the value of familiar outcomes in PFo can be accessed via IT but modulated only via the amygdala, which is essential for updating the hedonic value of foods (Blundell et al., 2001). This idea is consistent with the finding that monkeys with amygdala lesions or inactivations show stable preferences for particular classes of food-related objects, based on the long-term values of the associated foods, although they cannot modify their behavior after reinforcer devaluation (Malkova et al., 1997; Wellman et al., 2005; present study). This model also accounts for the intact performance of monkeys with perirhinal cortex lesions (Chudasama and Murray, 2004), in which many IT-PF connections are spared. According to this view, when monkeys are confronted with visual choices of objects, IT-PF interactions have at least two products: prospective coding of upcoming object choices (Murray and Gaffan, 2006) and prospective coding of the value of the expected outcome. Only in the reinforcer devaluation task are monkeys forced to choose objects according to the current, updated value of the associated foods, which relies on amygdala-PFo interactions (Baxter et al., 2000), and so only that task depends on the amygdala.

\section{References}

Aggleton JP, Passingham RE (1981) Syndrome produced by lesions of the amygdale in monkeys (Macaca mulatta). J Comp Physiol Psychol 95:961-977.

Aggleton JP, Passingham RE (1982) An assessment of the reinforcing properties of foods after amygdaloid lesions in rhesus monkeys. J Comp Physiol Psychol 96:71-77.

Barrett TW (1969) Studies of the function of the amygdaloid complex in Macaca mulatta. Neuropsychologia 7:1-12.

Baxter MG, Murray EA (2000) Reinterpreting the behavioural effects of amygdala lesions in nonhuman primates. In: The amygdala: a functional analysis, Ed 2 (Aggleton JP, ed), pp 545-568. Oxford: Oxford UP.

Baxter MG, Saunders RC, Murray EA (1998) Aspiration lesions of the amygdala interrupt connections between prefrontal cortex and temporal cortex in rhesus monkeys. Soc Neurosci Abstr 24:757.3.

Baxter MG, Hadfield WS, Murray EA (1999) Rhinal cortex lesions produce mild deficits in visual discrimination learning for an auditory secondary reinforcer in rhesus monkeys. Behav Neurosci 113:243-252.

Baxter MG, Parker A, Lindner CC, Izquierdo AD, Murray EA (2000) Control of response selection by reinforcer value requires interaction of amygdala and orbital prefrontal cortex. J Neurosci 20:4311-4319.

Baylis LL, Gaffan D (1991) Amygdalectomy and ventromedial prefrontal ablation produce similar deficits in food choice and in simple object discrimination learning for an unseen reward. Exp Brain Res 86:617-622.

Blundell P, Hall G, Killcross S (2001) Lesions of the basolateral amygdala disrupt selective aspects of reinforcer representation in rats. J Neurosci 21:9018-9026.

Browning PG, Easton A, Gaffan D (2007) Frontal-temporal disconnection abolishes object discrimination learning set in macaque monkeys. Cereb Cortex, in press.

Bussey TJ, Wise SP, Murray EA (2002) Interaction of ventral and orbital prefrontal cortex with inferotemporal cortex in conditional visuomotor learning. Behav Neurosci 116:703-715.

Butter CM (1969) Perseveration in extinction and in discrimination reversal tasks following selective frontal ablations in Macaca mulatta. Physiol Behav 4:163-171.

Butter CM, Mishkin M, Rosvold HE (1963) Conditioning and extinction of a food-rewarded response after selective ablations of frontal cortex in rhesus monkeys. Exp Neurol 7:65-75.

Chudasama Y, Murray EA (2004) Hippocampal lesions in rhesus monkeys disrupt emotional responses but not reinforcer devaluation effects. Soc Neurosci Abstr 30:84.8.

Gaffan D (1985) Hippocampus: memory, habit and voluntary movement. Philos Trans R Soc Lond B Biol Sci 308:87-99.

Gaffan D, Harrison S (1987) Amygdalectomy and disconnection in visual learning for auditory secondary reinforcement by monkeys. J Neurosci 7:2285-2292.
Goulet S, Dore FY, Murray EA (1998) Aspiration lesions of the amygdala disrupt the rhinal corticothalamic projection system in rhesus monkeys. Exp Brain Res 119:131-140.

Hikosaka K, Watanabe M (2000) Delay activity of orbital and lateral prefrontal neurons of the monkey varying with different rewards. Cereb Cortex 10:263-271.

Holland PC, Gallagher M (2004) Amygdala-frontal interactions and reward expectancy. Curr Opin Neurobiol 14:148-155.

Izquierdo A, Murray EA (2004a) Combined unilateral lesions of the amygdala and orbital prefrontal cortex impair affective processing in rhesus monkeys. J Neurophysiol 91:2023-2039.

Izquierdo A, Murray EA (2004b) Mediodorsal nucleus of the thalamus contributes to reinforcer devaluation effects in rhesus monkeys. Soc Neurosci Abstr 30:84.9.

Izquierdo A, Murray EA (2005) Opposing effects of amygdala and orbital prefrontal cortex lesions on the extinction of instrumental responding in macaque monkeys. Eur J Neurosci 22:2341-2346.

Izquierdo A, Suda RK, Murray EA (2004) Bilateral orbital prefrontal cortex lesions in rhesus monkeys disrupt choices guided by both reward value and reward contingency. J Neurosci 24:7540-7548.

Izquierdo A, Suda RK, Murray EA (2005) Comparison of the effects of bilateral orbital prefrontal cortex lesions and amygdala lesions on emotional responses in rhesus monkeys. J Neurosci 25:8534:8542.

Jones B, Mishkin M (1972) Limbic lesions and the problem of stimulusreinforcement associations. Exp Neurol 36:362-377.

Kalin NH, Shelton SE, Davidson RJ, Kelley AE (2001) The primate amygdala mediates acute fear but not the behavioral and physiological components of anxious temperament. J Neurosci 21:2067-2074.

King BM, Rossiter KN, Stines SG, Zaharan GM, Cook JT, Humphries MD, York DA (1998) Amygdaloid-lesion hyperphagia: impaired response to caloric challenges and altered macronutrient selection. Am J Physiol 275:R485-R493.

Klüver H, Bucy PC (1939) Preliminary analysis of functions of the temporal lobes in monkeys. Arch Neurol Psychiatry 42:979-1000.

Malkova L, Gaffan D, Murray EA (1997) Excitotoxic lesions of the amygdala fail to produce impairment in visual learning for auditory secondary reinforcement but interfere with reinforcer devaluation effects in rhesus monkeys. J Neurosci 17:6011-6020.

Malkova L, Lex CK, Mishkin M, Saunders RC (2001) MRI-based evaluation of locus and extent of neurotoxic lesions in monkeys. Hippocampus 11:361-370.

Meunier M, Bachevalier J, Murray EA, Malkova L, Mishkin M (1999) Effects of aspiration versus neurotoxic lesions of the amygdala on emotional responses in monkeys. Eur J Neurosci 11:4403-4418.

Munoz M, Mishkin M, Saunders RC (2001) Medial temporal removals disconnect rostral superior temporal gyrus from frontal cortex. Soc Neurosci Abstr 27:535.10.

Murray EA (1992) Medial temporal lobe structures contributing to recognition memory: the amygdaloid complex versus the rhinal cortex. In: The amygdala: neurobiological aspects of emotion, memory, and mental dysfunction (Aggleton JP, ed), pp 453-470. New York: Wiley.

Murray EA, Gaffan D (2006) Prospective memory in the formation of learning sets by rhesus monkeys (Macaca mulatta). J Exp Psychol Anim Behav Process 32:87-90.

Murray EA, Gaffan EA, Flint Jr RW (1996) Anterior rhinal cortex and amygdala: dissociation of their contributions to memory and food preference in rhesus monkeys. Behav Neurosci 110:30-42.

Murray EA, Baxter MG, Gaffan D (1998) Monkeys with rhinal cortex damage or neurotoxic hippocampal lesions are impaired on spatial scene learning and object reversals. Behav Neurosci 112:1291-1303.

Nemanic S, Alvarado MC, Price RE, Jackson EF, Bachevalier J (2002) Assessment of locus and extent of neurotoxic lesions in monkeys using neuroimaging techniques: a replication. J Neurosci Methods 121:199-209.

Padoa-Schioppa C, Assad JA (2006) Neurons in the orbitofrontal cortex encode economic value. Nature 441:223-226.

Parker A, Gaffan D (1998) Interaction of frontal and perirhinal cortices in visual object recognition memory in monkeys. Eur J Neurosci 10:3044-3057.

Pribram KH, Bagshaw M (1953) Further analysis of the temporal lobe syndrome utilizing frontotemporal ablations. J Comp Neurol 99:347-375. 
Ritter S, Hutton B (1995) Mercaptoacetate-induced feeding is impaired by central nucleus of the amygdala lesions. Physiol Behav 58:1215-1220.

Rolls ET (1999) The brain and emotion. New York: Oxford UP.

Schwartzbaum JS, Poulos DA (1965) Discrimination behavior after amygdalectomy in monkeys: learning set and discrimination reversals. J Comp Physiol Psychol 60:320-328.

Spiegler BJ, Mishkin M (1981) Evidence for the sequential participation of inferior temporal cortex and amygdala in the acquisition of stimulusreward associations. Behav Brain Res 3:303-317.

Stefanacci L, Clark RE, Zola SM (2003) Selective neurotoxic amygdala lesions in monkeys disrupt reactivity to food and object stimuli and have limited effects on memory. Behav Neurosci 117:1029-1043.
Tremblay L, Schultz W (1999) Relative reward preference in primate orbitofrontal cortex. Nature 398:704-708.

Wallis JD, Miller EK (2003) Neuronal activity in primate dorsolateral and orbital prefrontal cortex during performance of a reward preference task. Eur J Neurosci 18:2069-2081.

Weiskrantz L (1956) Behavioral changes associated with ablation of the amygdaloid complex in monkeys. J Comp Physiol Psychol 49:381-391.

Wellman LL, Gale K, Malkova L (2005) $\mathrm{GABA}_{\mathrm{A}}$-mediated inhibition of basolateral amygdala blocks reward devaluation in macaques. J Neurosci 25:4577-4586.

White NM, McDonald RJ (2002) Multiple parallel memory systems in the brain of the rat. Neurobiol Learn Mem 77:125-184. 